\title{
High Power and High Reliable 915 nm Lasers with Window Structure Fabricated by Impurity Free Vacancy Disordering (IFVD)
}

\author{
Hidehiro Taniguchi Non-member, Hirotatsu Ishii Non-member, Ryuichiro Minato Non-member, \\ Yutaka Ohki Non-member, Takeshi Namegaya Non-member, Akihiko Kasukawa Non-member \\ (Optical Device Dept. FITEL Photonics Laboratory R \& D Division, Furukawa Electric Co., Ltd.)
}

Keywords : semiconductor lasers, high power, catastrophic optical damage (COD), impurity free vacancy disordering (IFVD)

There are increasing demands for higher output power of 9xx $\mathrm{nm}$ laser diode. The output power is limited by sudden failure, which is caused by facet degradation leading to catastrophic optical damage (COD). A window structure with higher bandgap energy contributes to avoid the facet degradation. Quantum well (QW) intermixing is general technique for increasing the bandgap energy of window region. QW intermixing by impurity free vacancy disordering (IFVD) is very attractive because it doesn't give rise to the issue such as increase of free carrier absorption losses and leakage currents due to the electrically active impurities. A previous successful demonstration of IFVD, however, provided maximum output power of less than $10 \mathrm{~W}$. In this paper, we report high output power lasers with high performance IFVD window.

Intermixing is usually done by utilizing dielectric film, followed by rapid thermal annealing (RTA). By investigating IFVD process in detail, we found that the degree of intermixing depended on the properties of dielectric film. Two kinds of SiN films deposited on window and gain regions under respective optimum conditions were used. In RTA, the film on window region enhances generation of vacancies on semiconductor surface by $\mathrm{Ga}$ out-diffusion, while the film on gain region prevents generation of vacancies. The diffusion of vacancies induces quantum well intermixing, leading to bandgap shift.

For high output power laser, window region having a large bandgap difference $(\Delta \mathrm{Eg})$ with respect to gain region is required to protect the facet from high optical power density. Fig.1 shows photoluminescence spectrum peak shifts with respect to the as-grown. The blue shifts observed for the gain region were very small as less than $10 \mathrm{meV}$. It was found experimentally that intermixing in the gain region was suppressed thanks to the newly developed technique. On the other hand, large blue shifts were observed for the window region.

Fig.2 shows the output power characteristics for both lasers with window and without window structures. The maximum output power for a window laser exceeded $25.6 \mathrm{~W}$ at $30 \mathrm{~A}$ under pulsed operation, limited by our experimental set up. This is the one of the highest power for $100 \mu \mathrm{m}$-wide single emitter lasers. The laser without window structure suffered sudden failure caused by facet degradation at output power of about $15 \mathrm{~W}$.

The life test was performed at ACC condition under $20^{\circ} \mathrm{C}$ heatsink temperature, as shown in Fig. 3. The operation current of $6 \mathrm{~A}, 7 \mathrm{~A}, 8 \mathrm{~A}$ and $9 \mathrm{~A}$ correspond to output power of about 5W,6W, $7 \mathrm{~W}$ and $8 \mathrm{~W}$ respectively. We observed sudden failure for all lasers without window structure at 9A. On the other hand, all lasers with window structure have survived the test. We observed no degradation and no sudden failure for 5800 hours at 9A. It was clear that the window structure fabricated by our IFVD process

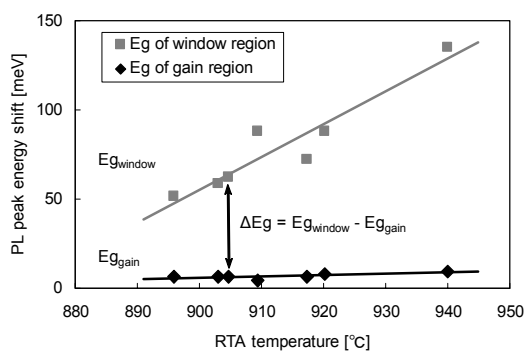

Fig. 1. PL energy shift as a function of RTA temperature

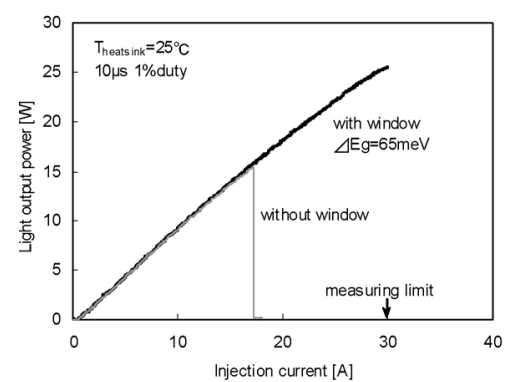

Fig. 2. L-I characteristics (pulsed operation)

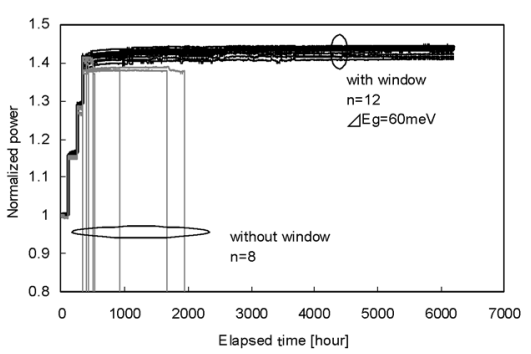

Fig. 3. Life test result at ACC conditon

suppressed facet degradation.

In summary, we have demonstrated high performance SCH-SQW lasers with window utilizing IFVD technique. A very high output power of $25.6 \mathrm{~W}$ at $30 \mathrm{~A}$ under pulsed operation was obtained without facet degradation. Moreover, no degradation and no sudden failure were observed for 5800 hours life test at $8 \mathrm{~W}-20^{\circ} \mathrm{C}$. We have, thus, realized the highest output power and high reliable lasers with IFVD window structure. ACKNOWLEDGMENT :

This work was supported by Innovative Technology Development of JST (Japan Science and technology Agency) 


\title{
IFVD 空構造による高出力高信頼性 $915 \mathrm{~nm}$ 半導体レーザ
}

\begin{tabular}{|c|c|c|c|}
\hline 非会員 & 谷口 英広* & 非会員 & 石井 \\
\hline 非会員 & 湊 龍一郎* & 非会員 & 大才 \\
\hline 非人 & 武* & 非会員 & w \\
\hline
\end{tabular}

\section{High Power and High Reliable 915 nm Lasers with Window Structure Fabricated by Impurity Free Vacancy Disordering (IFVD)}

Hidehiro Taniguchi*, Non-member, Hirotatsu Ishii*, Non-member, Ryuichiro Minato*, Non-member, Yutaka Ohki*, Non-member, Takeshi Namegaya*, Non-member, Akihiko Kasukawa*, Non-member

\begin{abstract}
We have demonstrated high performance broad area single emitter lasers with window structure fabricated by newly developed impurity free vacancy disordering (IFVD) technique. Vacancies induce quantum well intermixing, leading to bandgap shift. We have succeeded in obtaining the large bandgap shift in window region and maintaining the original bandgap in gain region simultaneously. We can control the bandgap difference. A very high output power of $25.6 \mathrm{~W}$ at $30 \mathrm{~A}$ under pulsed operation was obtained without facet degradation. This is the one of the highest power for $100 \mu \mathrm{m}$ wide single emitter lasers. Moreover, no degradation and no sudden failure were observed for 5800 hours life test at $8 \mathrm{~W}-20^{\circ} \mathrm{C}$. We have, thus, realized the highest output power and high reliable lasers with window structure fabricated by IFVD.
\end{abstract}

キーワード : 半導体レーザ, 高出力, COD (catastrophic optical damage), IFVD（impurity free vacancy disordering）

Keywords : semiconductor lasers, high power, catastrophic optical damage (COD), impurity free vacancy disordering (IFVD)

\section{1. まえがき}

9xx nm レーザダイオードは, EDFA 用励起光源, ファイ バーレーザ用励起光源として使用され，コスト低減の観点 から, さらなる高出力化が求められている。しかし, 高出 力化に伴い, COD (Catastrophic Optical Damage) と呼ばれる 端面劣化による突然死が問題となっている。この端面劣化 は次のように生じると理解されている。端面領域に存在す る表面準位が非発光再結合を促し，この再結合エネルギー は熱として消費され端面温度が上がる。温度上昇は, 端面 部分でのエネルギーギャップを小さくするため，端面部で の光吸収が増大し，これがさらに端面温度上昇を誘発する。 この一連のサイクルが瞬時に繰り返され, ついに端面溶融 を引き起こす。

COD を抑制する効果的な方法の一つとして空構造があ る。空構造は, 端面領域に, より大きなバンドギャップを 形成するもので, 光吸収を抑えることができ, 上記サイク

\footnotetext{
* 古河電気工業 (株) ファイテルフォトニクス研究所 半導体デバイス開発部

干290-8555 千葉県市原市八幡海岸通 6 番地

Optical Device Dept. FITEL Photonics Laboratory R \& D Division, Furukawa Electric Co., Ltd., 6, Yawata-kaigandori, Ichihara, Chiba $290-8555$
}

ルを断ち切ることができる。

量子井戸混晶化は，バンドギャップを大きくする技術の 一つである。混晶化の手法には 2 種類あり，第一に不純物 を使った混晶化，第二に不純物フリーの混晶化（IFVD; Impurity Free Vacancy Disordering) である。前者では Si や Zn に代表される不純物がよく使用されるが，フリーキャリア 吸収の増加やリーク電流の増加を引き起こすため, 空構造 にとって，好ましくない。

そのため, 端面劣化を防ぐいろいろな技術の中で(1)〜(3), $\operatorname{IFVD}^{(4)(5)}$ は不純物を介さないことを特長として注目されて おり，大きなバンドギャップ，低いロスを持った高性能な 空を実現できる技術として非常に期待されている。実際, 近年 IFVD の適用により, 最高光出力 $8 \mathrm{~W}$ のレーザが報告さ れている(6)。本論文では, より高い光出力, より高性能な空 をもったレーザについて報告する。

\section{2. レーザ構造と IFVD}

IFVD プロセスをレーザに適用する場合，空領域を選択的 に混晶化させ，それ以外の領域を混晶化させず保護するこ とが重要である。混晶化は誘電体膜成膜, それに続く RTA (Rapid Thermal Annealing) プロセスによって行われ, 混晶化 の選択性がレーザ基本特性や空性能を決める。高出力レー 


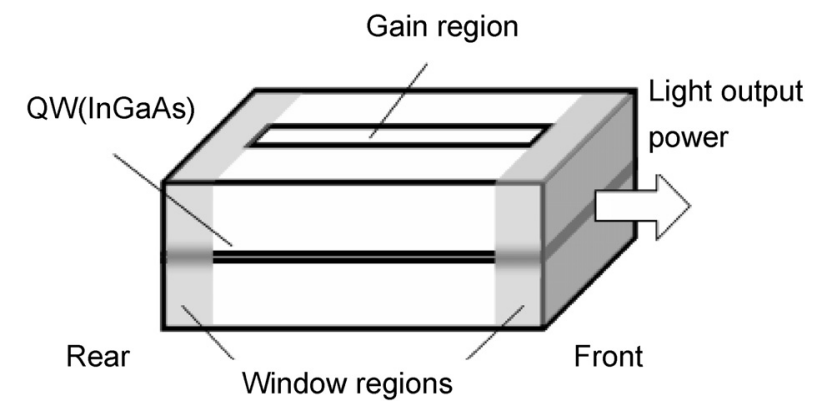

Fig. 1. Schematic view of a laser with window structure.

ザでは, 端面での光密度が大きいため, 空領域と保護領域 でのバンドギャップ差が大きいほど，COD が生じにくい高 性能な窓になる。バンドギャップ差の増大のためだけには 直接的に RTA 温度を上げることが有効であるが，高温熱処 理は保護領域まで混晶化させることになり，レーザ基本特 性が劣化してしまう。それではバンドギャップ差が大きく ても高出力化は達成されない。そこで, 我々は, 高出力化 と高信頼性化を両立させるために, 保護領域でのバンドギ ヤップを維持しつつ, 同時に, 空領域のバンドギャップシ フトを大きくするための研究を行った。

本研究に使われたレーザ構造を Fig.1 に示す。MOCVD 法 (Metal-organic Chemical Vapor Deposition) によりエピタキシ ヤル成長で作られた SCH-SQW（Separate Confinement Heterostructure Single Quantum Well）レーザである。材料は, $\mathrm{GaAs}$ コンタクト層, $\mathrm{AlGaAs}$ クラッド層, $\mathrm{InGaAs} / \mathrm{AlGaAs}$ 活性層で構成されている。活性層の厚みは $10 \mathrm{~nm}$ であり, In 組成比は 0.09 である。IFVD プロセスでは，まず，GaAs コ ンタクト層上の空領域とゲイン領域に，それぞれ最適化さ れた SiN 薄膜を成膜する。この薄膜の性質は, 量子井戸混 晶化の度合いに大きく影響を与える。RTA において，空領 域の N リッチな $\mathrm{SiN}$ 薄膜は, $\mathrm{GaAs}$ コンタクト層表面の $\mathrm{Ga}$ 原子を引き抜き, 空孔生成を促進させる。一方, ゲイン領 域のストイキオメトリな $\mathrm{Si}_{3} \mathrm{~N}_{4}$ 薄膜は空孔生成を抑制させ る ${ }^{(4)}$ 。主に空領域で生成された空孔は拡散し, 量子井戸の混 晶化を促す。混晶化された領域のバンドギャップは広げら れ, 空としての機能が付与される。その後, SiN 薄膜は取り 除かれ，電極を形成し，レーザが出来上がる。

\section{3. 量子井戸混晶化}

Fig. 2 は, $910^{\circ} \mathrm{C}-30 \mathrm{~s}$ の RTA 後に, 空領域とゲイン領域の それぞれから得られた PL (Photoluminescence) スペクトル である。また, リファレンスとしてエピ成長後に得られた サンプルも示す。窓領域では, 混晶化により短波側へ波長 シフトしていることがわかる。また，スペクトルの形状は どれもほぼ同じであり, 半值幅の増加はない。これは, RTA プロセスがレーザに重大なダメージを与えなかったことを 意味する。

Fig. 3 は，RTA 温度に対する PL エネルギーシフトを示す グラフである。PL エネルギーシフトは, RTA 前後での PL スペクトルシフトとして定義した。このシフト量は, 混晶

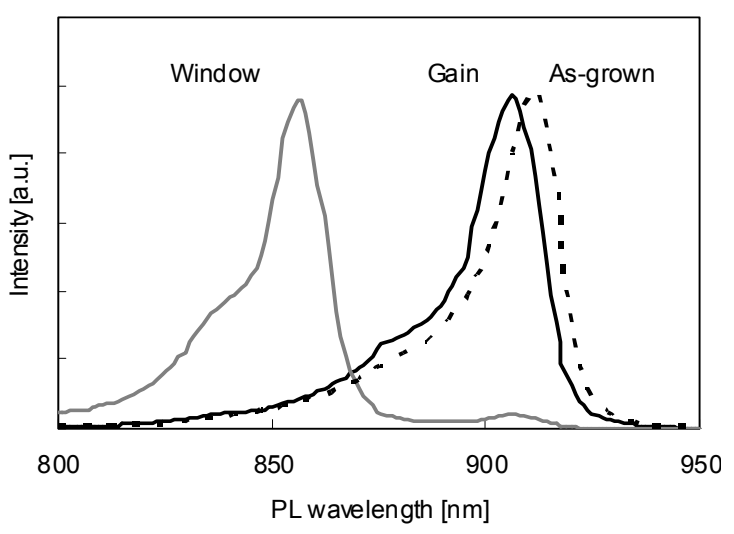

Fig. 2. Typical Photoluminescence spectra of the laser with window structure (after $910^{\circ} \mathrm{C} 30$ s RTA).

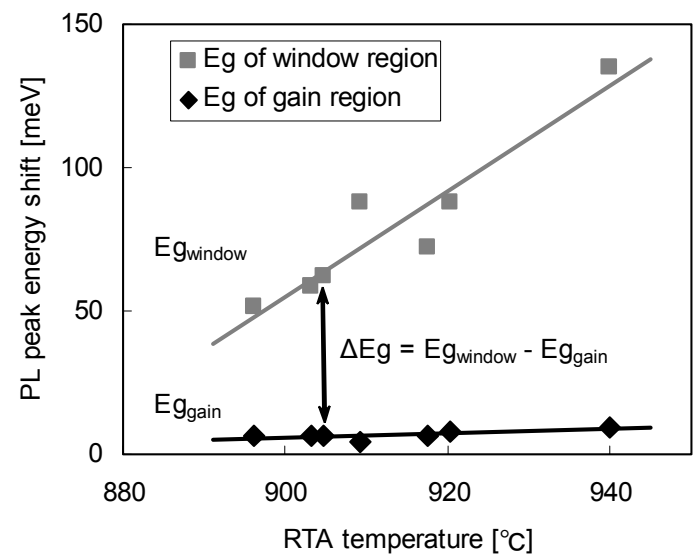

Fig. 3. Photoluminescence energy shift as a function of RTA temperature (30s).

化の度合いに対応する。ゲイン領域で見られるエネルギー シフト $\left(\mathrm{Eg}_{\text {gain }}\right)$ は $10 \mathrm{meV}$ 以下と非常に小さく, ゲイン領域 での混晶化は, 我々が新しく開発した技術によって抑えら れたことがわかる。一方，空領域においては， $140 \mathrm{meV} も の$ 大きなブルーシフトが得られた。空領域で見られるエネル ギーシフト $\left(\mathrm{Eg}_{\text {window }}\right)$ は, RTA 温度の増加に伴って大きく なり，ゲイン領域と空領域のエネルギーシフト差 $(\Delta \mathrm{Eg})$ も大きくなる。Fig. 3 に示したデータは, 複数の成膜バッチ, エピ成長バッチから構成されている。大きな $\Delta \mathrm{Eg}$ を確保で きること, また RTA 温度に対して系統的に $\Delta \mathrm{Eg}$ の上昇が得 られていることは, 再現よく $\Delta \mathrm{Eg}$ がコントロールされてい ると結論できる。

Fig. 4 は, RTA 後における量子井戸の断面 TEM 像 （Transmission Electron Microscope）である。写真における白 い帯は InGaAs 活性層に対応し, 黒い地帯は, $\mathrm{AlGaAs}$ 光ガ イド層に対応する。写真 (a)のゲイン領域では, $\mathrm{InGaAs} / \mathrm{AlGaAs}$ のはっきりとした境界が見られるが，写真 (b)の空領域では, 対応する境界がぼけている。これは, 意 図した領域には IFVDによって量子井戸が混晶化され, 意図 していない領域は混晶化されないということに相当し, 選 択的な IFVD が確立されたことを意味する。 


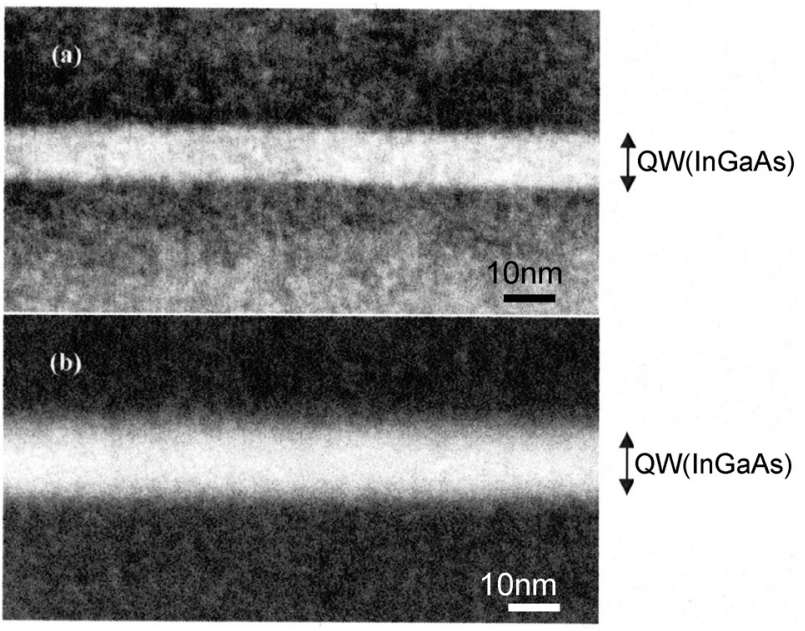

Fig. 4. Cross-sectional TEM images of QW after RTA. (a)TEM image for gain region (b)TEM image for window region.

\section{4.レーザ特性}

〈4·1〉 光学的特性 レーザチップは, 熱膨張を合わ せた $\mathrm{CuW}$ プレートに An-Sn 半田を使ってジャンクションダ

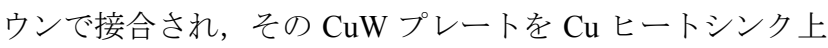
に組み立てた。Fig. 5 は, 空構造付きと空構造なしの両方の レーザの駆動電流-光出力特性を示す。ストライプ幅は $100 \mu \mathrm{m}$ であり, キャビティー長は, $3.6 \mathrm{~mm}$ である。空構造 付きレーザにおける $\Delta \mathrm{Eg}$ は, $65 \mathrm{meV}$ である。空構造なしレ ーザ（リファレンスレーザ）の端面近傍はアンポンプな領 域となっている。

測定条件は，ヒートシンク温度 $25^{\circ} \mathrm{C}, 1 \%$ サイクル $10 \mu \mathrm{s}$ 幅パルス電流とした。空構造の有無によらず，試作したレ ーザの典型的な閾值は $500 \mathrm{~mA}$ であり，スロープ効率は 0.95W/A であった。つまり, 空構造付きレーザは, IFVDに よる高温プロセスを経たにもかかわらず，レーザ基本特性 における劣化は見られていない。加えて, 空構造なしレー ザは, 電流約 $17 \mathrm{~A}$, 光出力約 $15 \mathrm{~W}$ で端面劣化が原因の突然 死に至ったのに対して, 空構造付きレーザの最大光出力は, 実験設備の測定限界の 30A において, 25.6W にまで達した。 これは, $100 \mu \mathrm{m}$ 幅のシングルエミッタレーザにおいては, 最高峰の数值であり, 我々は実際のレーザ構造に IFVDを適 用し，COD 対策として非常に効果的な空構造の作製に成功 した。

Fig. 6 は, 空構造付きレーザにおける, CW（Continuous Wave）駆動条件下での駆動電流-光出力特性を示す。ヒート シンク温度は, $15^{\circ} \mathrm{C}-60^{\circ} \mathrm{C}$ 範囲で変化させている。最大光 出力は， $15^{\circ} \mathrm{C}, 18 \mathrm{~A}$ において，14.8W にまで達した。閾值温 度依存を表す特性温度 $\mathrm{T}_{0}$ は，200K であった。

$\langle 4 \cdot 2\rangle \quad$ 信頼性評価 ヒートシンク温度 $20^{\circ} \mathrm{C}, \mathrm{ACC}$ (Automatic Current Control) 条件下において，階段上のエー ジングテストを行った（Fig.7）。この図は，駆動電流を 6A, 7A，8A，9A と階段状に上げた場合の, 時間に対する光出力

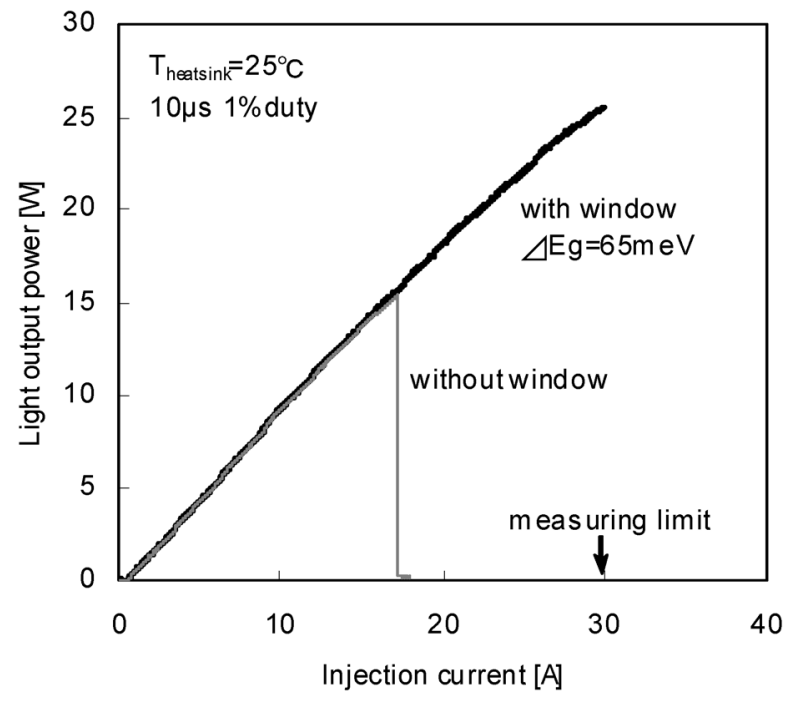

Fig. 5. L-I characteristics (pulsed operation).

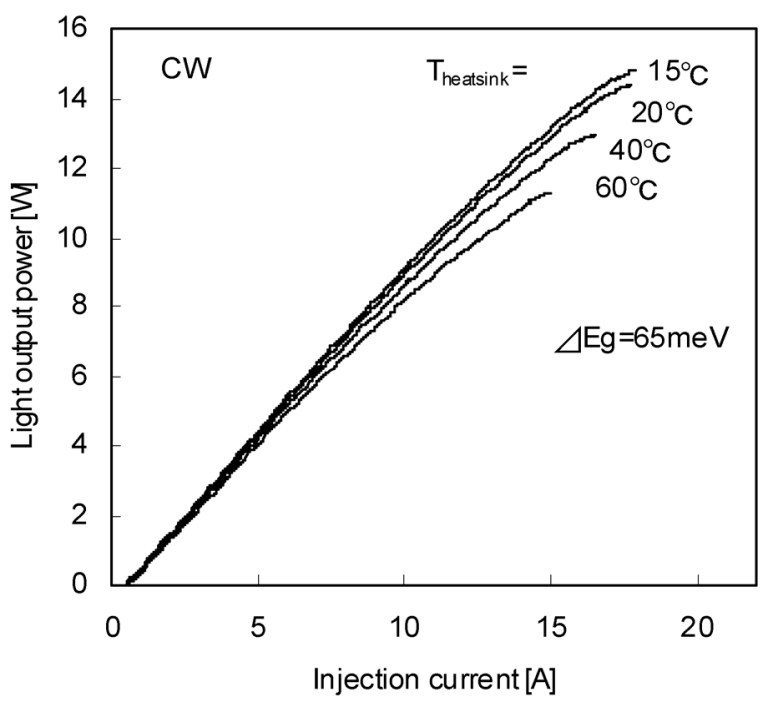

Fig. 6. L-I characteristics (CW operation).

の変化率を示す。サンプルは, 空構造付きレーザ 12 個, 空 構造なしレーザ 8 個である。空構造付きレーザにおける $\triangle \mathrm{Eg}$ は，60meV である。駆動電流の 6A，7A，8A，9A は， それぞれ, おおよその光出力で $5 \mathrm{~W}, 6 \mathrm{~W}, 7 \mathrm{~W}, 8 \mathrm{~W}$ に対応 する。

空構造なしレーザにおいては, 駆動電流を上げ, より過 酷な条件になることにより，9A の段階で突然死が起こりす べて故障してしまった。一方, 空構造付きレーザは, テス ト中すべて生き残り, 9A で 5800 時間を経過したが, 漸次 劣化や突然死は見られず，高い信頼性を保持している。こ れは，我々のIFVDによって作製された空が，エージングに おいても有効に㗢いていることを示している。

\section{5. 結論}

我々は, IFVD 技術を開発し, 同一ウェハ面内で選択的に 空領域とゲイン領域のバンドギャップをコントロールする 


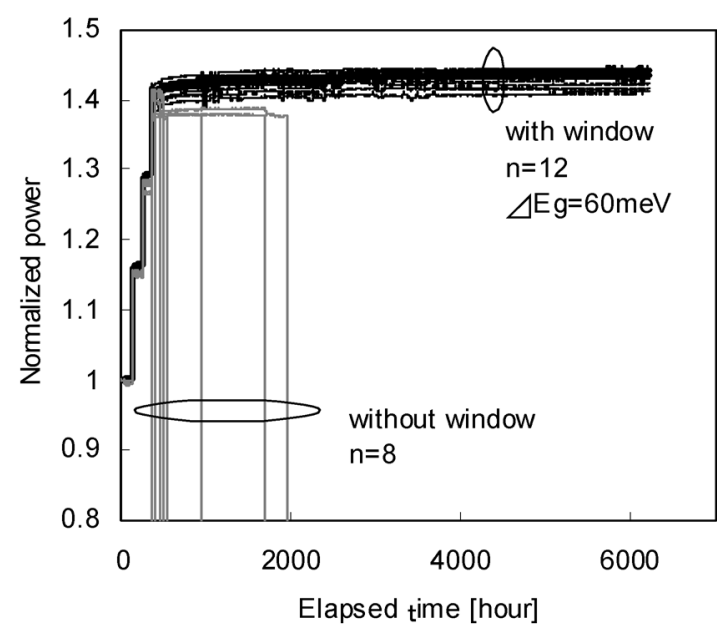

Fig. 7. Life test result of the lasers with window and without window structures at ACC condition under $20^{\circ} \mathrm{C}$ heatsink temperature.

ことに成功した。さらに，この技術を $100 \mu \mathrm{m}$ ストライプ幅 の SCH-SQW レーザに適用し, その結果, $100 \mu \mathrm{m}$ 幅のシン グルエミッタレーザにおいて最高峰となる, 最大光出力 25.6W（30A のパルス条件下）を得た。また，エージングテ ストにおいては，8W 条件下で 5800 時間の間，漸次劣化や 突然死が見られなかった。以上の様に，端面劣化対策とし て IFVD 技術を用いた空構造付きレーザの作製に成功し, 高 出力化と高信頼性化に有効であることを確認した。

\section{謝 辞}

本研究の一部は, (独) 科学技術振興機構（JST）から受 託した革新技術開発研究事業によるものである。

(平成 19 年 8 月 27 日受付，平成 19 年 12 月 17 日再受付)

\section{文献}

(1) E. Latta, A. Moser, A. Oosenbrug, M. Gasser, and Th. Forster : "Reliability of high-power AlGaAs SQW grinsch lasers", 12th IEEE International Semiconductor Laser Conference, Conference Digest, pp.276-276 (1990)

( 2 ) J. K. Lee, K. H. Park, D. H. Jang, H. S. Cho, C. S. Park, K. E. Pyun, and J. Jeong : "Improvement of Catastrophic Optical Damage (COD) Level for High-Power $0.98 \mu \mathrm{m}$ GaInAs-GaInP Laser Diodes Using Impurity Induced Layer Disordering”, IEEE Photon. Technol. Lett., Vol.10, pp.1226-1228 (1998)

( 3 ) K. Hiramoto, M. Sagawa, T. Kikawa, and S. Tsuji : "High-Power and Highly Reliable Operation of Al-Free InGaAs-InGaAsP $0.98-\mu \mathrm{m}$ Lasers with a Window Structure Fabricated by Si Ion Implantation", IEEE J. Select. Topics Quantum Electron., Vol.5, pp.817-820 (1999)

(4) D. G. Deppe, L. J. Guido, N. Holonyak, Jr., K. C. Hsieh, R. D. Burnham, R. L. Thornton, and T. L. Paoli : "Stripe-geometry quantum well heterostructure AlxGa1-xAs-GaAs lasers defined by defect diffusion", Appl. Phys. Lett., Vol.49, pp.510-512 (1986)

( 5 ) P. L. Gareso, M. Buda, L. Fu, H. H. Tan, and C. Jagadish : "Suppression of thermal atomic interdiffusion in C-doped InGaAs/AlGaAs quantum well laser structures using TiO2 dielectric layers", Appl. Phys. Lett., Vol.85, pp.5583-5585 (2004)

(6) Y. Yamada, Y. Yamada, T. Fujimoto, and K. Uchida : "High power and highly reliable $980 \mathrm{~nm}$ lasers with window structure using Impurity Free Vacancy Disordering”, Proc. SPIE, Vol.5738, pp.40-46 (2005)

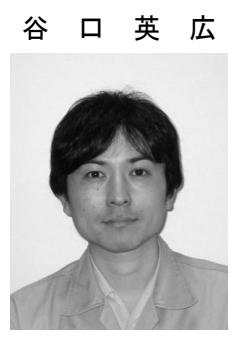

（非会員）２001 年東京工業大学大学院修士課程 修了。同年, 古河電気工業（株）入社。半導体 デバイス開発部所属。半導体レーザモジュール の設計開発に携わり, 現在, 9xx-nm レーザの チップ開発に従事。主として, 端面保護技術を 担当している。

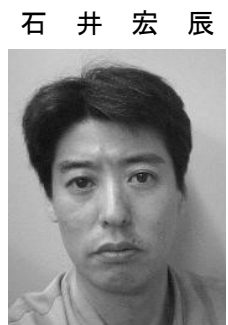

（非会員）1992 年北海道大学大学院博士課程修 了。1993 年古河電気工業（株）入社。半導体研 究開発センター所属。化合物半導体材料の結晶 成長の研究開発に携わり, 現在, 半導体レーザ の開発に従事。工学博士。応用物理学会会員。

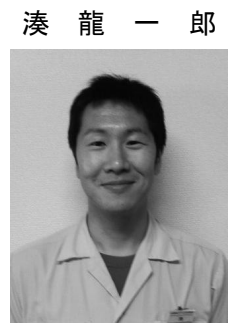

（非会員）２０00 年早稲田大学大学院修士課程修 了。同年, 古河電気工業（株）入社。半導体デ バイス部所属。主として，化合物半導体材料の エピタキシャル成長を担当している。

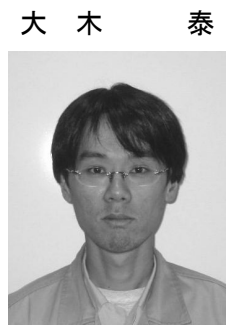

（非会員） 1999 年東京大学大学院修士課程修 了。同年, 古河電気工業（株）入社。半導体デ バイス開発部所属。主として, 半導体レーザチ ップの設計開発を担当している。応用物理学会 会員。

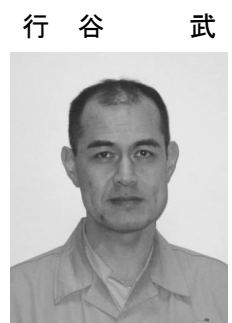

（非会員）1988 年横浜国立大学大学院修士課程 修了。同年, 古河電気工業（株）入社。半導体 デバイス開発部所属。主として，半導体レーザ チップの設計開発を担当している。

粕 川 秋 彦

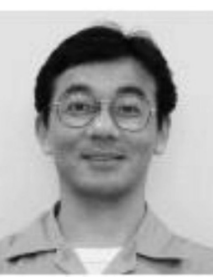
2001 年櫻井健二郎氏記念賞。工学博士。電子情報通信学会, 応用物 理学会, IEEE 会員。 